\title{
Penile Doppler ultrasonography and elastography evaluation in patients with erectile dysfunction
}

\author{
Namik Kemal Altinbas ${ }^{1 A, B, C, C, E, E, F}$, Nurullah Hamidi ${ }^{2 B, C, D, E}$ \\ 'Department of Radiology, Faculty of Medicine, Ankara University, Ankara, Turkey \\ ${ }^{2}$ Atatürk Training and Research Hospital, Urology, Ankara, Turkey
}

\section{Abstract}

Purpose: To evaluate the relationship between erection grade, erectile function score, Doppler ultrasonography (US) indexes, and elasticity score (ES) according to Doppler US diagnosis in patients with erectile dysfunction (ED).

\begin{abstract}
Material and methods: Real-time strain type penile elastography was performed during penile Doppler US examination for 88 patients with ED. The diagnosis according to Doppler US was determined. Erection score according to the Erection Hardness Grading Scale was evaluated. A scoring for erectile function was performed with the International Index of Erectile Function (IIEF-5), and the Sexual Health Inventory for Men (SHIM) was defined. The relationships, according to Doppler diagnosis, of ES, IIEF-5 score, SHIM scale, and erection score were evaluated.
\end{abstract}

Results: Among the patients, 50 (57\%) had abnormal penile Doppler US findings. According to Doppler US findings, patients were classified as normal $(n=38)$, borderline for arterial insufficiency $(n=4)$, arterial insufficiency $(n=5)$, and venous insufficiency $(n=41)$. The lowest erection hardness grades and IIEF- 5 scores were detected in patients with arterial failure. When compared to the normal group, in terms of ES, the arterial failure borderline group and venous failure group had lower scores, and the arterial failure group had a higher score. However, the only significant difference was obtained in the left cavernous body of the venous failure group.

Conclusions: Sonoelastography seems to add additional value for determination of stiffness of the penile cavernous body in routine evaluation of ED.

Key words: elastography, erectile dysfunction, IIEF score, penile Doppler ultrasonography.

\section{Introduction}

Erectile dysfunction (ED) or impotence is characterised by persistent inability to develop and maintain an erection of the penis in men for intercourse [1]. ED is one of the most common sexual disorders in males, and it affects about half of the male population between 40 and 70 years old [2,3]. ED is a neurovascular phenomenon modulated by hormonal, local biochemical, and biomechanical factors [4-7]. Erectile dysfunction may signal serious underlying diseases, such as hypertension [2], diabetes mellitus [8,9], cardiovascular disease [10,11], peripheral vascular disease [12], and other endocrine [13] and neurological disorders [14,15].
Penile Doppler US provides real-time evaluation of cavernosal vascular flow dynamics. Colour and spectral penile Doppler ultrasonography (US) is a highly accurate tool for assessing patients with erectile dysfunction $[16,17]$ and it has been used for diagnostic purposes since its first application in 1985 [18]. However, it has been reported that penile Doppler US might not give accurate results in diagnosis of venous insufficiency in some cases $[19,20]$. During the procedure, many patients also suffer from pain during papaverine injection. Moreover, priapism can develop in a minority of the patients who undergo penile Doppler US [21]. Because penile Doppler US does not seem to be a perfect test, we aimed to improve

\section{Correspondence address:}

Dr. Namik Kemal Altinbas, Department of Radiology, Faculty of Medicine, Ankara University, Ibni Sina H, 06230, Ankara, Turkey, e-mail: namikaltin@gmail.com Authors' contribution:

A Study design · B Data collection · C Statistical analysis · D Data interpretation · E Manuscript preparation · F Literature search · G Funds collection 
the diagnosis by adding sonoelastography, and tried to find out if elastography had any positive effects on diagnosis of ED.

As a relatively new sonographic method, elastography is currently under investigation for tissue characterisation of several anatomic sites. More recently, elastography has been used in urology practice for evaluation of the stiffness of the cavernous body of the penis $[22,23]$. Elastography is a completely non-invasive procedure different from penile Doppler US, and it provides additional information to the information obtained in penile Doppler US by the examination of the tissue stiffness.

Our objective was to evaluate the relationship between erection grade, erectile function score, Doppler US indexes, and elasticity score (ES) according to Doppler US diagnosis in patients with ED.

\section{Material and methods}

\section{Study group}

This study was performed as a prospective study in the Department of Radiology between April 2016 and April 2017. All patients gave written, informed consent for sonographic evaluation and for this study. All procedures were performed in accordance with the Declaration of Helsinki for human subjects, and our Institutional Review Board approved the study.

We included patients who had ED complaints referred from urology department to radiology department for penile Doppler US to determine the aetiology of ED. The exclusion criteria were the following: (1) patients who had a history of penile and/or urethral surgery, (2) history of radiotherapy, radical pelvic surgery, (3) medical therapy that might cause ED, (4) neurological, hormonal, and psychological disorders that might cause ED.

A total of 88 patients who met the inclusion criteria were enrolled in the study.

\section{Ultrasonography}

In all patients, urological examinations and consultations were performed by the same clinician, and the procedure of penile Doppler US was indicated. Penile Doppler US was indicated for those patients with ED who did not respond to oral phosphodiesterase type 5 inhibitors.

Sonographic evaluations were performed by the same radiologist, having experience in elastography. Grey-scale US, Doppler US, and elastography examinations were performed with a Logiq S7 Expert machine (GE Healthcare, Milwaukee, WI) equipped with a 9L-D linear-array probe. In the examination room, with the patient lying in a supine position and the penis held in the anatomical position, $2 \mathrm{ml}$ (60 $\mathrm{mg}$ ) of papaverine was injected with an insulin injection needle into the lateral aspect of the proximal third of the right cavernous body via
US guidance under sterile conditions. On grey-scale US, probable lesions such as Peyronie's plaques were evaluated by dorsal and ventral approach in longitudinal and transverse planes. After the injection, a dynamic assessment of the spectral Doppler waveform in the cavernosal arteries was performed on the proper Doppler angle at 30-60 degrees. Spectral Doppler US findings including peak systolic velocity (PSV) and end-diastolic velocity (EDV) were recorded, and the diagnosis based on Doppler US was determined. Post-injection measurements including PSV, EDV, visual maximum tumescence, and erection hardness were taken from 0 to 20 minutes. This sonographic examination was terminated after spectral Doppler measurements taken at the $20^{\text {th }}$ minute. The patients were warned about probable priapism. If the PSV value was below $25 \mathrm{~cm} / \mathrm{s}$ during the examination, the diagnosis was arterial insufficiency. When the PSV was ranged from 25 to $30 \mathrm{~cm} / \mathrm{s}$, the diagnosis was borderline for arterial insufficiency. PSV values above $30 \mathrm{~cm} / \mathrm{s}$ were considered normal for arteriogenic function. When a good diastolic reversal or below $5 \mathrm{~cm} / \mathrm{s}$ EDV values were achieved during the examination, venous insufficiency was ruled out. When the EDV value was still above $5 \mathrm{~cm} / \mathrm{s}$ at the end of the examination, the diagnosis was venous insufficiency $[17,18,24-27]$. Penile elastography was performed for all patients during penile Doppler US examination at the $10^{\text {th }}-12^{\text {th }}$ minutes for each of the patients to achieve the maximum erection hardness. During the sonographic examination, none of the patients achieved more erection grade than that which we assigned. Slight repetitive manual compressions were performed keeping the transducer perpendicular to the skin during the evaluation of strain type elastography. On the images, region of interest (ROI) selection was placed on the right and left corpus cavernosum using a free-hand drawing tool along each border. ES was obtained as ESR (elasticity score of right corpus cavernosum) and ESL (elasticity score of left corpus cavernosum) by elastographic analysis. ESA (average elasticity score of right and left corpus cavernosum) was calculated. The ES is a semi-quantitative value, and while a low ES indicates soft tissue, a higher ES indicates stiff tissue. When evaluated by colour perspective, while red colour reflects less stiff tissue, blue colour reflects more stiff tissue. Green colour reflects medium stiff tissue of the entire area undergoing elastography. The described strain type elastography method represents relative information about hardness [28-30].

\section{Erection Hardness Grading Scale}

The time, which each of the patients achieved the maximum erection hardness, the scoring was graded by the radiologist who performed the examination according to the Erection Hardness Grading Scale (EHGS) during penile Doppler US examination to provide standardisation in scoring. According to the scale: grade 0 represents 'not 
enlarged', grade 1 represents 'larger but not hard', grade 2 represents 'hard but not hard enough for penetration', grade 3 represents 'hard enough for penetration but not completely hard', and grade 4 represents 'completely hard and fully rigid' [31].

\section{International Index of Erectile Function and Sexual Health Inventory for Men}

The patients were asked five questions about erection confidence, erection hardness, maintenance ability, maintenance frequency, and intercourse satisfaction based on the International Index of Erectile Function (IIEF) questionnaire, and the Sexual Health Inventory for Men (SHIM) level was defined $[32,33]$. Each participant answered the questionnaire individually, without any help. Maximum effort was made to ensure privacy when the participants were completing the questionnaire. Each IIEF item was scored on a five-point ordinal scale, in which lower values represent poorer sexual function. Possible scores for the IIEF- 5 ranged from 5 to 25 . Severity of ED was classified into five categories as: severe (IIEF-5 scores; $5-7$ ), moderate (scores; $8-11$ ), mild to moderate (scores; 12-16), mild (scores; 17-21), and no ED (scores; 22-25).

\section{Statistical analysis}

Statistical analyses were performed using SPSS software version 15.0 for Windows (IBM Corporation, Armonk, NY). Descriptive statistics of continuous variables are given as mean \pm standard deviation (SD) and median (interquartile range). To compare groups, the Mann-Whitney $U$ test was used for non-normally distributed data and Student's $t$-test was used for normally distributed data. The degree of association between variables was calculated by Spearman's correlation coefficient. Differences among the four groups for non-normally distributed variables were evaluated by Kruskal-Wallis variance analysis. When the $p$-value from the Kruskal-Wallis test statistics was statistically significant, a multiple comparison test was used to determine which group differed from which of the others [34]. Receiver operating characteristic (ROC) curves were used to describe the performance of diagnostic values of ES variables between the normal group $(n=38)$ and the ED group (borderline for arterial insufficiency, arterial insufficiency, and venous insufficiency) ( $n=50)$ according to Doppler diagnosis. The area under the corresponding curves was calculated as described by Hanley and McNeil [35]. $P<0.05$ was considered statistically significant.

\section{Results}

There were a total of 88 patients with a mean age of 49.20 \pm 14.08 (19-75) years. The erection hardness grade, IIEF-5 score, and SHIM level are shown in Table 1. Peak systolic velocity (PSV), end-diastolic velocity (EDV), elasticity score right (ESR), elasticity score left (ESL), and elasticity score average (ESA) indexes of each group are shown in Table 2. Of the 88 patients, 50 (57\%) had abnormal penile Doppler US findings. According to Doppler US findings, patients were classified as normal $(n=38)$ (Figure 1), borderline for arterial insufficiency $(n=4)$ (Figure 2), arterial insufficiency (all were diabetic) $(n=5)$ (Figure 3), and venous insufficiency $(n=41)$ (Figure 4$)$.

Age of the patients, PSV, EDV, erection hardness grade, IIEF-5 score, SHIM level, ESR, ESL, and ESA indexes were compared among the groups based on the Doppler diagnosis. There were statistically significant differences among the groups, as shown in Table 3.

Peyronie's plaques were detected in four patients with grey-scale US. In the study group there were accompanying health problems including diabetes mellitus (type 1 and 2), hypertension, hyperlipidaemia, coronary artery disease, peripheral arterial disease, ankylosing spondylitis, scleroderma, old penile trauma, male infertility, varicocelectomy, multiple sclerosis, familial Mediterranean fever, and partial pancreatectomy.

When compared with the normal group, in terms of ES, the arterial failure borderline group and venous failure group had lower scores, and the arterial failure group had a higher score. The only statistically significant difference was obtained for the left corpus cavernosum of the venous failure group (Tables 3 and 4).

When compared with the normal group, in the arterial insufficiency borderline group, EHGS, PSV, and EDV indexes had a statistically significant difference, whereas IIEF-5, SHIM, ESR, ESL, and ESA values did not have any significant difference.

Table 1. Erection hardness grade, IIEF-5 score, and SHIM level of each group based on Doppler diagnosis

\begin{tabular}{|l|c|c|c|}
\hline Penile Doppler diagnosis & $\begin{array}{c}\text { Erection hardness grade (0-4) } \\
\text { mean } \pm \text { SD (min.-max.) }\end{array}$ & $\begin{array}{c}\text { IIEF-5 score } \\
\text { mean } \pm \text { SD; median (IQR) }\end{array}$ & $\begin{array}{c}\text { SHIM (1-5) } \\
\text { mean } \pm \text { SD (min.-max.) }\end{array}$ \\
\hline Normal $(n=38)$ & $3.71 \pm 0.69(1-4)$ & $17.03 \pm 3.64 ; 17(5.25)$ & $3.66 \pm 0.85(2-5)$ \\
\hline Arterial failure borderline $(n=4)$ & $1.75 \pm 0.5(1-2)$ & $15 \pm 6.27 ; 16.5(11.5)$ & $3 \pm 1.41(1-4)$ \\
\hline Arterial failure $(n=5)$ & $1.6 \pm 0.55(1-2)$ & $7.8 \pm 1.64 ; 7(3)$ & $1.4 \pm 0.55(1-2)$ \\
\hline Venous failure $(n=41)$ & $2.8 \pm 0.51(1-4)$ & $13.85 \pm 3.24 ; 14(4)$ & $3.02 \pm 0.69(1-4)$ \\
\hline Total $(n=88)$ & $3.08 \pm 0.87(1-4)$ & $14.93 \pm 4.16 ; 15(6)$ & $3.2 \pm 0.95(1-5)$ \\
\hline
\end{tabular}

IIEF - International Index of Erectile Function, SHIM - Sexual Health Inventory for Men, IQR - interquartile range 
Table 2. Peak systolic velocity (PSV), end-diastolic velocity (EDV), elasticity score right (ESR), elasticity score left (ESL), and elasticity score average (ESA) values of each group based on Doppler diagnosis

\begin{tabular}{|l|c|c|c|c|c|}
\hline Penile Doppler diagnosis & $\begin{array}{c}\text { PSV }(\mathrm{cm} / \mathrm{s}) \\
\text { mean } \pm \text { SD; } \\
\text { median (IQR) }\end{array}$ & $\begin{array}{c}\text { EDV }(\mathrm{cm} / \mathrm{s}) \\
\text { mean } \pm \text { SD; } \\
\text { median (IQR) }\end{array}$ & $\begin{array}{c}\text { ESR mean } \pm \text { SD; } \\
\text { median (IQR) }\end{array}$ & $\begin{array}{c}\text { ESL mean } \pm \text { SD; } \\
\text { median (IQR) }\end{array}$ & $\begin{array}{c}\text { ESA mean } \pm \text { SD; } \\
\text { median (IQR) }\end{array}$ \\
\hline Normal $(n=38)$ & $63.7 \pm 18.87 ;$ & $-5.96 \pm 7.84 ;$ & $1.18 \pm 0.45 ;$ & $1.21 \pm 0.47 ;$ & $1.19 \pm 0.43 ;$ \\
& $58.6(27.72)$ & $-5.9(8.93)$ & $1.1(0.43)$ & $1.1(0.45)$ & $1.1(0.43)$ \\
\hline Arterial failure borderline & $28.75 \pm 1.2 ;$ & $6.5 \pm 1.9 ;$ & $1.07 \pm 0.89 ;$ & $1.05 \pm 0.77 ;$ & $1.06 \pm 0.83 ;$ \\
$(n=4)$ & $28.9(2.3)$ & $6.7(3.55)$ & $0.7(1.43)$ & $0.7(1.2)$ & $0.7(1.31)$ \\
\hline Arterial failure $(n=5)$ & $19.06 \pm 2.58 ;$ & $6.96 \pm 1.47 ;$ & $1.44 \pm 0.23 ;$ & $1.24 \pm 0.19 ;$ & $1.34 \pm 0.17 ;$ \\
& $17.3(4.7)$ & $7.4(2.8)$ & $1.6(0.40)$ & $1.3(0.35)$ & $1.4(0.25)$ \\
\hline Venous failure $(n=41)$ & $56.23 \pm 24.86 ;$ & $9.1 \pm 5.65 ;$ & $1.07 \pm 0.39 ;$ & $0.99 \pm 0.31 ;$ & $1.03 \pm 0.34 ;$ \\
& $48.3(22.45)$ & $7.3(3.15)$ & $0.9(0.5)$ & $0.9(0.35)$ & $1.0(0.4)$ \\
\hline Total $(n=88)$ & $56.1 \pm 23.96 ;$ & $2.35 \pm 9.73 ;$ & $1.14 \pm 0.44 ;$ & $1.10 \pm 0.42 ;$ & $1.12 \pm 0.41 ;$ \\
& $52.45(27.23)$ & $5.2(11.98)$ & $1(0.5)$ & $1.05(0.4)$ & $1.05(0.5)$ \\
\hline
\end{tabular}

IQR - interquartile range
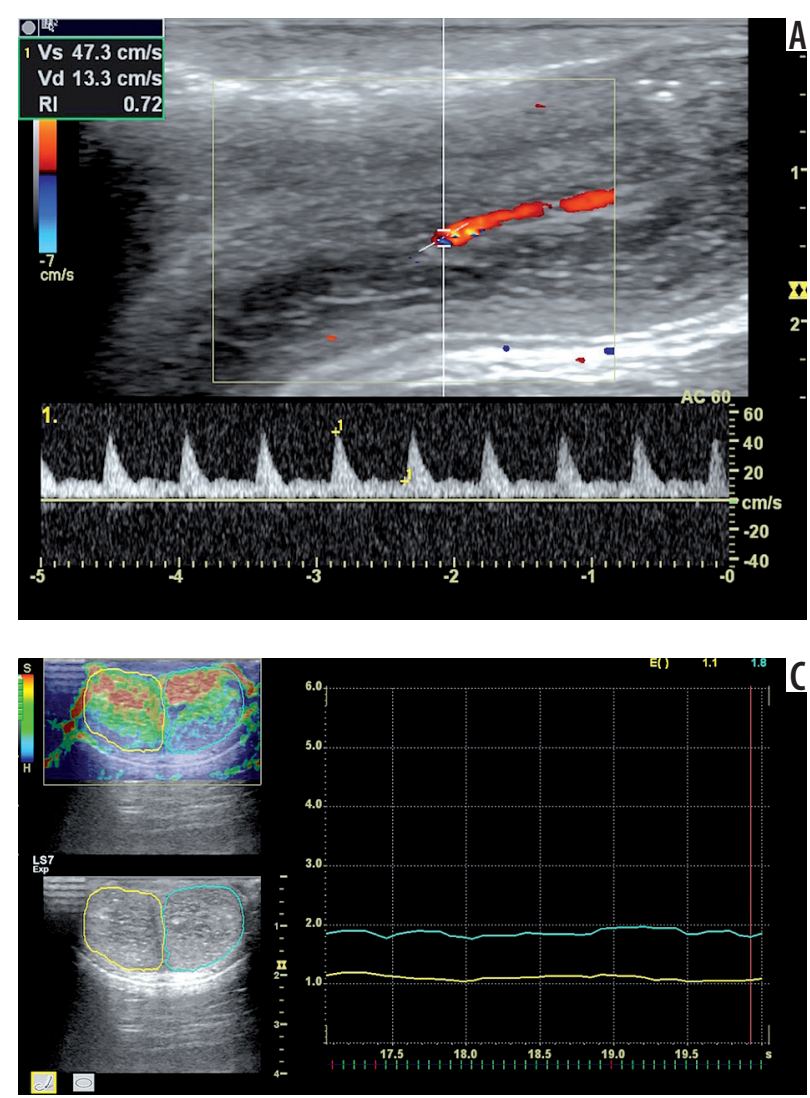

In the arterial insufficiency group, EHGS, IIEF-5, SHIM, PSV, and EDV values had statistically significant differences when compared with the normal group, whereas ESR, ESL, and ESA values did not differ.

When compared with the normal group, in the venous insufficiency group, EHGS, IIEF-5, SHIM, EDV, and ESL indexes had statistically significant differences, whereas PSV, ESR, and ESA values did not have a significant difference.

Erection hardness grade was mostly detected as grade 3 in patients with venous insufficiency, grade 1 and 2 in

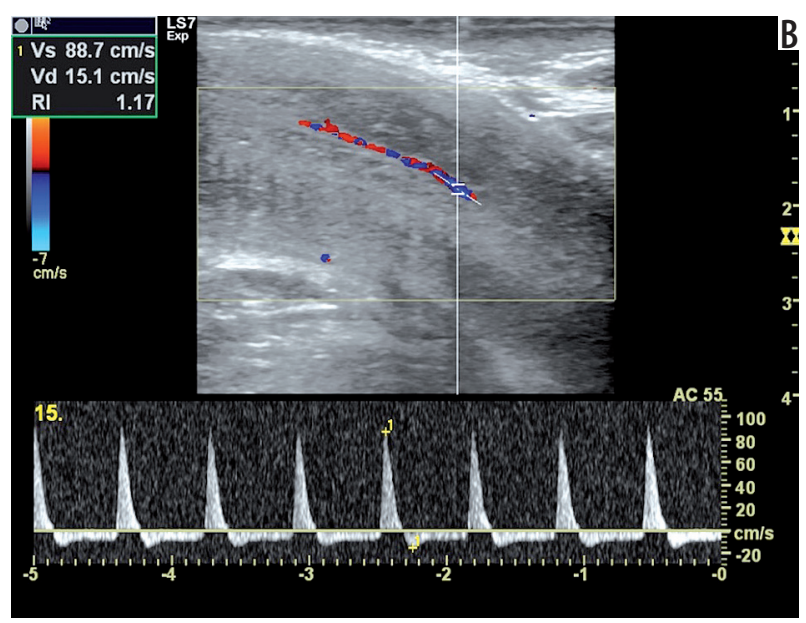

Figure 1. A 22-year-old man, normal according to Doppler diagnosis. Doppler images show PSV $47.3 \mathrm{~cm} / \mathrm{s}$ at the first minute (A) and EDV $-15.10 \mathrm{~cm} / \mathrm{s}$ at the $15^{\text {th }}$ minute (B) during examination. The elastogram shows elasticity scores of 1.10 (right cavernous body) and 1.80 (left cavernous body) (C). The other findings are EHGS of 4 (fully rigid), IIEF-5 score of 22, and SHIM scale of 5 (No ED). On the same night as the examination, priapism was detected in this patient

patients with arterial problems, and grade 4 in normal patients according to Doppler findings. The lowest erection hardness grade and IIEF-5 score were detected in the patients with arterial failure (Table 1).

ROC curves were performed (Figure 5) and area under the curve (AUC) was reported by comparison of the normal $(n=38)$ and ED group $(n=50)$ (Table 4$)$. The best cut-off values with sensitivity and specificity were determined between the normal and ED groups. If the cut-off value was taken as less than or equal to 0.95 for ESR, then ED was present with $48 \%$ sensitivity and $74 \%$ specificity. 

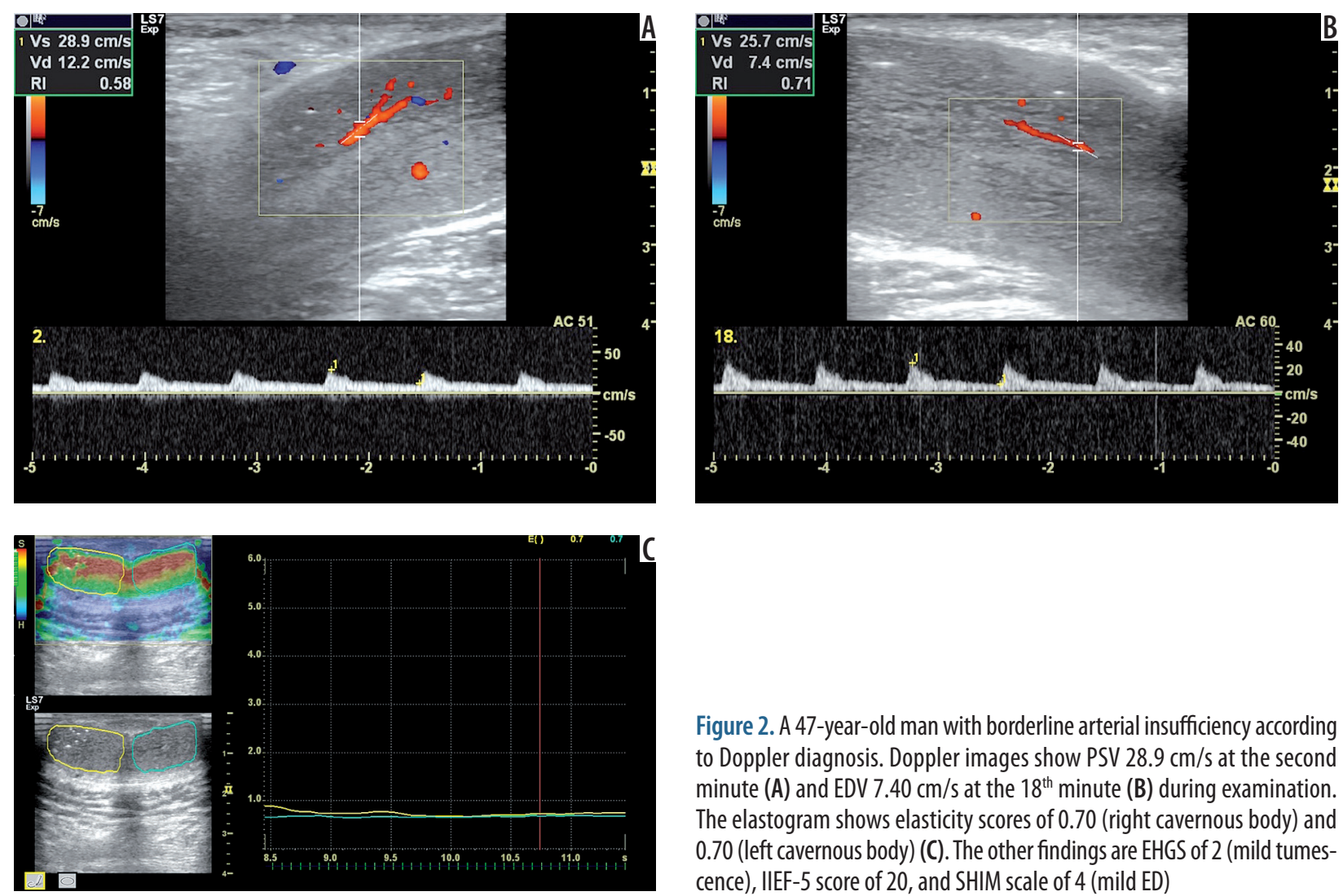

Figure 2. A 47-year-old man with borderline arterial insufficiency according to Doppler diagnosis. Doppler images show PSV $28.9 \mathrm{~cm} / \mathrm{s}$ at the second minute (A) and EDV $7.40 \mathrm{~cm} / \mathrm{s}$ at the $18^{\text {th }}$ minute (B) during examination. The elastogram shows elasticity scores of 0.70 (right cavernous body) and 0.70 (left cavernous body) (C). The other findings are EHGS of 2 (mild tumescence), IIEF-5 score of 20, and SHIM scale of 4 (mild ED)
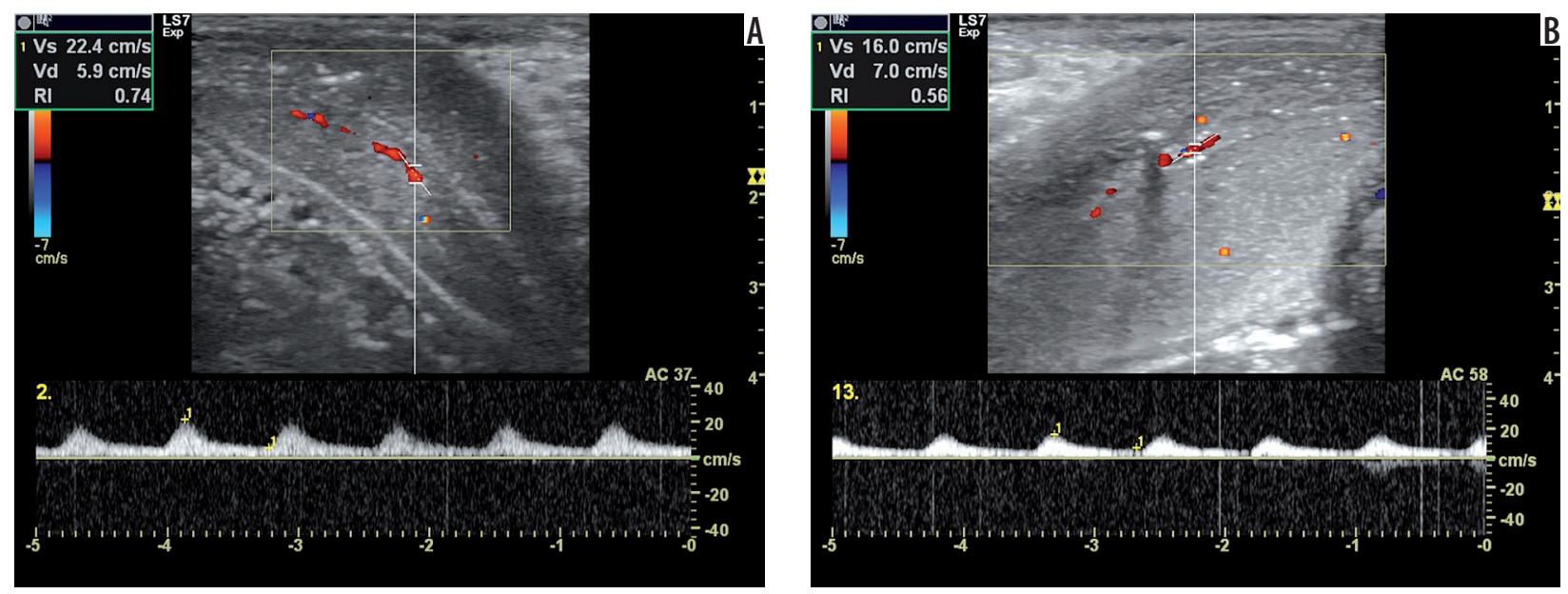

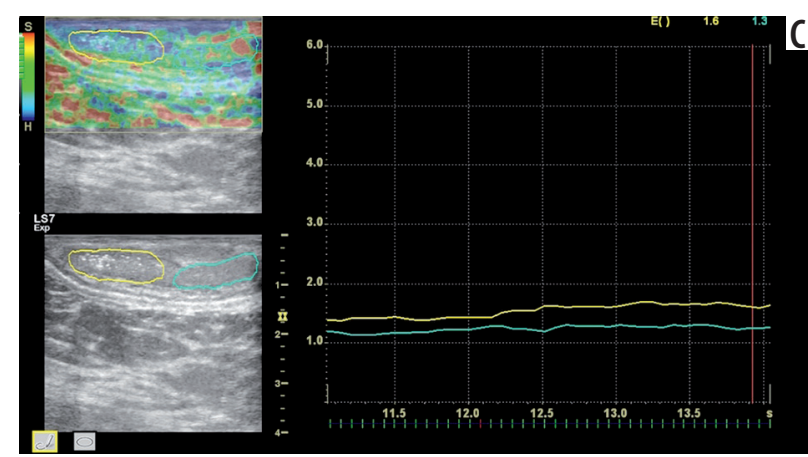

If the cut-off value was taken as $\leq 1.15$ for ESL, then ED was present with $72 \%$ sensitivity and $47 \%$ specificity. If the cut-off value was taken as $\leq 0.875$ for ESA, then ED was present with $38 \%$ sensitivity and $82 \%$ specificity.
Figure 3. A 70-year-old man with arterial insufficiency according to Doppler diagnosis. Doppler images show PSV $22.4 \mathrm{~cm} / \mathrm{s}$ at the second minute (A) and EDV $7.00 \mathrm{~cm} / \mathrm{s}$ at the $13^{\text {th }}$ minute (B) during examination. The elastogram shows elasticity scores of 1.60 (right cavernous body) and 1.30 (left cavernous body) (C). The other findings are EHGS of 1 (flaccid), IIEF-5 score of 7, and SHIM scale of 1 (severe). The patient had diabetes mellitus and coronary arterial disease with bypass surgery

The correlation analysis between erectile function score, Doppler US indexes, and ES according to Doppler US diagnosis was performed. A negative weak correlation was found between IIEF-5 score and EDV $(r=-0.421$, 

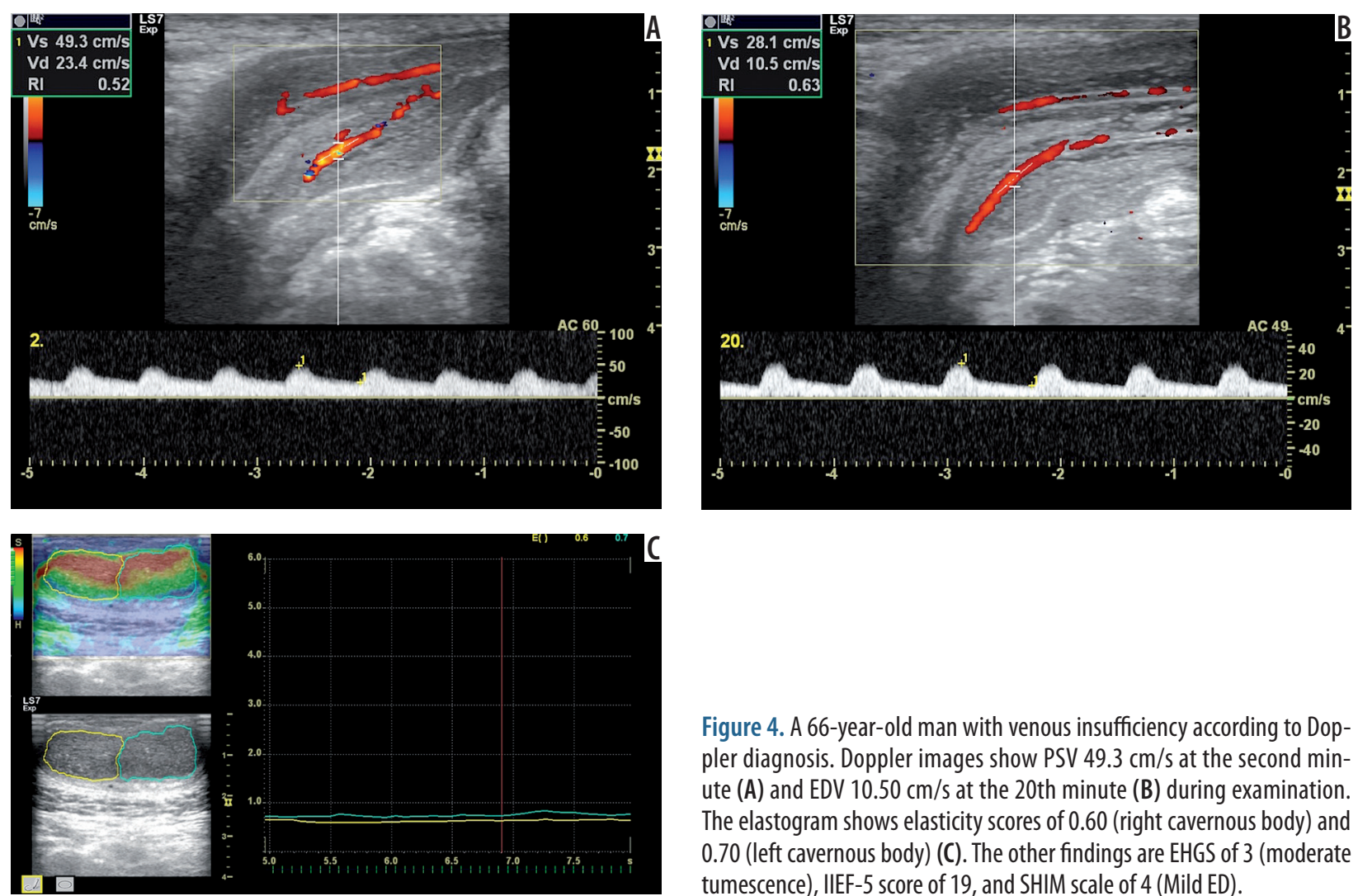

Figure 4. A 66-year-old man with venous insufficiency according to Doppler diagnosis. Doppler images show PSV $49.3 \mathrm{~cm} / \mathrm{s}$ at the second minute (A) and EDV $10.50 \mathrm{~cm} / \mathrm{s}$ at the 20th minute (B) during examination. The elastogram shows elasticity scores of 0.60 (right cavernous body) and 0.70 (left cavernous body) (C). The other findings are EHGS of 3 (moderate tumescence), IIEF-5 score of 19, and SHIM scale of 4 (Mild ED).

Table 3. Comparison of age of the patients, peak systolic velocity (PSV), end-diastolic velocity (EDV), erection hardness grade, International Index of Erectile Function (IIEF-5) score, Sexual Health Inventory for Men (SHIM) level, elasticity score right (ESR), elasticity score left (ESL), and elasticity score average (ESA) indexes among the groups based on Doppler diagnosis

\begin{tabular}{|c|c|c|c|c|c|}
\hline \multirow[t]{2}{*}{ Factor } & \multicolumn{4}{|c|}{ Penile Doppler diagnosis } & \multirow[t]{2}{*}{$p$ value } \\
\hline & Normal & $\begin{array}{l}\text { Arterial failure } \\
\text { borderline }\end{array}$ & Arterial failure & Venous failure & \\
\hline $\begin{array}{l}\text { Age (mean } \pm S D) \\
\text { (min.-max.) }\end{array}$ & $\begin{array}{c}42 \pm 14.98 \\
(19-72)\end{array}$ & $\begin{array}{c}53.75 \pm 8.3 \\
\quad(47-64)\end{array}$ & $\begin{array}{c}62 \pm 7.18 \\
(53-70)\end{array}$ & $\begin{array}{c}53.88 \pm 10.91 \\
(29-75)\end{array}$ & $<0.001$ \\
\hline $\begin{array}{l}\text { PSV (mean } \pm \text { SD) } \\
\text { (median; IQR) }\end{array}$ & $\begin{array}{l}63.7 \pm 18.9 \\
58.6 ; 27.72 \\
\end{array}$ & $\begin{array}{c}28.75 \pm 1.2 \\
28.9 ; 2.3\end{array}$ & $\begin{array}{c}19.06 \pm 2.58 \\
17.3 ; 4.7\end{array}$ & $\begin{array}{c}56.23 \pm 24.86 \\
48.3 ; 22.45 \\
\end{array}$ & $<0.001$ \\
\hline $\begin{array}{l}\text { EDV (mean } \pm \text { SD) } \\
\text { (median; IQR) }\end{array}$ & $\begin{array}{c}-5.96 \pm 7.84 \\
-5.9 ; 8.93 \\
\end{array}$ & $\begin{array}{l}6.5 \pm 1.9 \\
6.7 ; 3.55\end{array}$ & $\begin{array}{c}6.96 \pm 1.47 \\
7.4 ; 2.8\end{array}$ & $\begin{array}{c}9.1 \pm 5.65 \\
7.3 ; 3.15\end{array}$ & $<0.001$ \\
\hline $\begin{array}{l}\text { Erection hardness grade (mean } \pm \text { SD) } \\
\text { (min.-max.) }\end{array}$ & $\begin{array}{c}3.71 \pm 0.69 \\
(1-4)\end{array}$ & $\begin{array}{c}1.75 \pm 0.5 \\
(1-2)\end{array}$ & $\begin{array}{c}1.6 \pm 0.55 \\
(1-2)\end{array}$ & $\begin{array}{c}2.8 \pm 0.51 \\
(1-4)\end{array}$ & $<0.001$ \\
\hline $\begin{array}{l}\text { IIEF-5 Score } \\
\text { (mean } \pm \text { SD) } \\
\text { (median; IQR) }\end{array}$ & $\begin{array}{c}17.03 \pm 3.6 \\
17 ; 5.25 \\
\end{array}$ & $\begin{array}{l}15 \pm 6.27 \\
16.5 ; 11.5\end{array}$ & $\begin{array}{c}7.8 \pm 1.64 \\
7 ; 3\end{array}$ & $\begin{array}{c}13.85 \pm 3.24 \\
14 ; 4\end{array}$ & $<0.001$ \\
\hline $\begin{array}{l}\text { SHIM (mean } \pm \text { SD) } \\
\text { (min.-max.) }\end{array}$ & $\begin{array}{c}3.66 \pm 0.85 \\
(2-5) \\
\end{array}$ & $\begin{array}{c}3 \pm 1.41 \\
(1-4)\end{array}$ & $\begin{array}{c}1.4 \pm 0.55 \\
(1-2)\end{array}$ & $\begin{array}{c}3.02 \pm 0.69 \\
(1-4)\end{array}$ & $<0.001$ \\
\hline $\begin{array}{l}\text { ESR (mean } \pm \text { SD) } \\
\text { (median; IQR) }\end{array}$ & $\begin{array}{c}1.18 \pm 0.45 \\
1.1 ; 0.43\end{array}$ & $\begin{array}{c}1.08 \pm 0.89 \\
0.7 ; 1.43\end{array}$ & $\begin{array}{c}1.44 \pm 0.23^{a} \\
1.6 ; 0.40\end{array}$ & $\begin{array}{c}1.07 \pm 0.39 \\
0.9 ; 0.5\end{array}$ & 0.048 \\
\hline $\begin{array}{l}\text { ESL (mean } \pm \text { SD) } \\
\text { (median; IQR) }\end{array}$ & $\begin{array}{c}1.21 \pm 0.47 \\
1.1 ; 0.45\end{array}$ & $\begin{array}{c}1.05 \pm 0.77 \\
0.7 ; 1.2\end{array}$ & $\begin{array}{c}1.24 \pm 0.19^{b} \\
1.3 ; 0.35\end{array}$ & $\begin{array}{c}0.99 \pm 0.31^{c} \\
0.9 ; 0.35\end{array}$ & 0.026 \\
\hline $\begin{array}{l}\text { ESA (mean } \pm S D) \\
\text { (median; IQR) }\end{array}$ & $\begin{array}{c}1.19 \pm 0.43 \\
1.1 ; 0.43\end{array}$ & $\begin{array}{c}1.06 \pm 0.83 \\
0.7 ; 1.31\end{array}$ & $\begin{array}{c}1.34 \pm 0.17^{d} \\
1.4 ; 0.25\end{array}$ & $\begin{array}{c}1.03 \pm 0.34 \\
1.0 ; 0.4\end{array}$ & 0.030 \\
\hline
\end{tabular}

'Different from both AF borderline and VF ( $p=0.016$ and $p=0.018$, respectively)

${ }^{b}$ Different from both AF borderline and VF ( $p=0.032$ and $p=0.041$, respectively) 'Different from normal $(p=0.027)$

dDifferent from both AF borderline and VF ( $p=0.016$ and $p=0.017$, respectively)

Kruskal-Wallis ANOVA test and multiple comparison test were used.

$I Q R$ - interquartile range 
$p<0.001)$, and between PSV and $\operatorname{EDV}(r=-0.240$, $p=0.025)$. A positive strong correlation was found between ESR and ESL $(r=0.824, p<0.001)$, ESR and ESA $(r=0.956, p<0.001)$, and ESL and ESA $(r=0.948$, $p<0.001)$. The results of correlation analysis between IIEF-5 score and ESA $(r=-0.167, p=0.119)$, PSV and ESA $(r=-0.068, p=0.527)$, and EDV and ESA $(r=-0.140$, $p=0.119)$ were not statistically significant.

Priapism was observed in two young patients, aged 22 and 31 years, who had normal type penile Doppler US findings according to Doppler results with fully rigid erection.

\section{Discussion}

Penile erection occurs with a complex interaction between neural, arterial, venous, and sinusoidal systems. Any defect in one of these systems can result in ED that is a serious health dilemma affecting both men and their partners.

While Doppler US is a highly preferred method in the evaluation of ED [36], sonoelastography is a new, noninvasive method that promises new findings in this area [37]. Based on this idea, we aimed to evaluate whether sonoelastography has any effect on the diagnosis of ED. Our findings suggested that sonoelastography might provide additional information on the stiffness of the corpus cavernosum of the penis.

As ED can have psychogenic, organic (endocrine disorders, neurogenic, morphological penile abnormalities, and drug-induced), or mixed aetiology [24,36], vascular pathologies categorised as arterial (arteriogenic impotence) or venous (venogenic impotence) insufficiency can cause ED $[24,36]$. Vasculogenic ED has been shown to be the most common aetiology of organic ED in the literature [36]. Abnormal Doppler outcome (57\%) in our study population showed the importance of vascular aetiology in patients with ED complaints in accordance with the literature [38-41]. In addition to this data, we categorised Doppler findings in terms of the Doppler diagnosis as normal $(n=38,43 \%)$, borderline for arterial insufficiency $(n=4,5 \%)$, arterial insufficiency $(n=5,6 \%)$, and venous insufficiency ( $n=41,47 \%)$ among the patients with ED, and recorded that the majority of cases had venous Doppler abnormality.

There are some studies in the literature using elastography, including real-time strain sonoelastography or shear wave elastography (SWE), on penile structure and penile mass, such as Peyronie's plaques [22,42-44]. Stiffness of the penile cavernous body reflects the changes in tissue structure and composition of corpus cavernosum penis, which includes decreased sinusoids, and this results in occlusion and fibrosis [3,22]. Based on the fact that the stiffness of the corpus cavernosum of the penis has an important impact on the erectile function, Zhang et al. evaluated the stiffness of the penile cavernous body with
Table 4. Area under the curve according to the comparison of normal and erectile dysfunction (ED) groups

\begin{tabular}{|l|c|c|c|} 
& AUC \pm SE & $95 \%$ Cl for AUC & $p$ value \\
\hline ESR & $0.561 \pm 0.062$ & $0.440-0.683$ & 0.326 \\
\hline ESL & $0.625 \pm 0.060$ & $0.507-0.742$ & $0.046^{*}$ \\
\hline ESA & $0.590 \pm 0.061$ & $0.470-0.710$ & 0.150 \\
\hline
\end{tabular}

ESR - elasticity score right, ESL - elasticity score left, ESA - elasticity score average, AUC - area under the curve, $\mathrm{SE}$ - standard error, $\mathrm{Cl}$ - confidence interval, ${ }^{*}$ statistically significant

The area under the corresponding curves was calculated as described by Hanley and McNeil [18]

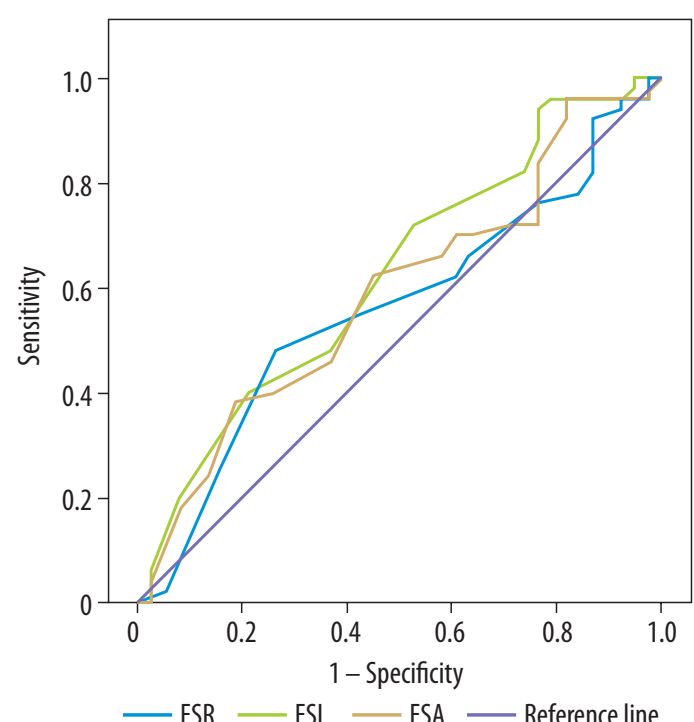

Figure 5. ROC curves were used to describe the performance of the diagnostic value of $E S$ variables between the normal and $E D$ groups based on the Doppler diagnosis

SWE on 40 healthy volunteers and concluded that SWE could serve as a non-invasive method [22]. In a study conducted by Inci et al. the authors drew similar conclusions [44]. Some studies, using sonoelastography on Peyronie's plaques, reported that sonoelastography provided additional and useful information in detecting penile lesions $[42,43]$.

Two recent reports evaluating the ES to obtain data on penile cavernous body stiffness have been published. In the study conducted by Turkay et al. [37] the authors compared two groups, in which ED patients and healthy volunteers were included, using SWE, without performing penile Doppler US and/or papaverine injection. They reported that SWE had high specificity and positive predictive value in the radiological evaluation of ED patients. On the other hand, the obtained cut-off values with strain type elastographic evaluation of ED did not achieve a diagnostic level with low sensitivity and specificity in our study. In another study conducted by Zhang et al. [45] the authors used ultrasound vibro-elastography technique to measure the viscoelasticity of the penis in 10 patients with ED or Peyronie's disease. They performed assessments before and after erectogenic drug injection and reported significant increases in viscoelasticity of the penis after erectogenic injection, validating the ability of the ultrasound vibro-elastography technique to measure dynamic changes in erection. 
In our study, we used strain elastography with elasticity scores ranging from an absolute value of zero (softest) to six (hardest). When we compared the groups in terms of elasticity scores, the arterial failure borderline group and the venous failure group had lower scores (less stiff), and the arterial failure group had a higher score (stiffer) than the normal group. A statistically significant difference was recorded only in the left corpus cavernosum of the penis in the venous failure group. This might be because of the papaverine injection with an insulin needle into the right cavernous body via US guidance. Therefore, this significant difference in the left (no needle injection side) cavernous body of the venous failure group might be considered more valuable.

With papaverine injection, priapism can be seen in the patients as a short-term complication. In our study group, priapism was observed in two young patients $(2.3 \%)$, aged 22 and 31 years, who had normal type penile Doppler US findings according to Doppler results with fully rigid erection. In the literature, Kilic et al. reported that priapism developed in $2.68 \%$ of patients in their series who were treated successfully [21]. In our opinion, attention should be paid especially to young patients with fully rigid erection during the penile Doppler examination.

The findings in the study are subject to limitations. First, caution must be applied to the small sample size of arterial insufficiency and borderline for arterial insufficiency groups. The total number in those groups should be increased. The second limitation is the heterogeneity of the study group. All patients were given the same amount of intracavernosal injection, and re-dosing was not performed. Therefore, we might have obtained a higher rate of false positive venous leakage. Other sensitive/specific tools such as arteriography, dynamic infusion cavernosometry, or cavernosography may also be performed to compare the additional benefits of elastography. Future studies, which will evaluate aforementioned comparisons, would be useful.

In conclusion, real-time strain elastography can easily be performed to detect the stiffness of the corpus cavernosum penis accompanied by Doppler US in patients with ED. Our results revealed that ultrasound elastography could provide additional useful information on the stiffness of the cavernous body along with Doppler diagnosis. Therefore, elastography may be performed concomitantly with penile US to obtain data on stiffness of corpus cavernosum penis in routine clinical practice.

\section{Conflict of interest}

The authors report no conflicts of interest.

\section{References}

1. NIH Consensus Conference. Impotence. NIH Consensus Development Panel on Impotence. JAMA 1993; 270: 83-90.

2. Heikkilä A, Kaipia A, Venermo M, et al. Relationship of blood pressure and erectile dysfunction in men without previously diagnosed hypertension. J Sex Med 2017; 14: 1336-1341.

3. Feldman HA, Goldstein I, Hatzichristou DG, et al. Impotence and its medical and psychosocial correlates: results of the Massachusetts Male Aging Study. J Urol 1994; 151: 54-61.

4. Williams SK, Melman A. Novel therapeutic targets for erectile dysfunction. Maturitas 2012; 71: 20-27.

5. Andersson KE, Wagner G. Physiology of penile erection. Physiol Rev 1995; 75: 191-236.

6. Andersson KE. Pharmacology of penile erection. Pharmacol Rev 2001; 53: 417-450.

7. Giuliano F, Rampin O. Neural control of erection. Physiol Behav 2004; 83: 189-201.

8. Altinbas NK, Hamidi N, Yagci C. Penile Doppler ultrasound findings in diabetic patients with erectile dysfunction. Ege J Med 2017; 56: 193-199.

9. Anwar Z, Sinha V, Mitra S, et al. Erectile dysfunction: An underestimated presentation in patients with diabetes mellitus. Indian J Psychol Med 2017; 39: 600-604.

10. Blumentals WA, Gomez-Caminero A, Joo S, et al. Should erectile dysfunction be considered as a marker for acute myocardial infarction? Results from a retrospective cohort study. Int J Impot Res 2004; 16: 350-353.
11. Rastrelli G, Corona G, Lotti F, et al. Flaccid penile acceleration as a marker of cardiovascular risk in men without classical risk factors. J Sex Med 2014; 11: 173-186.

12. Blumentals WA, Gomez-Caminero A, Joo S, et al. Is erectile dysfunction predictive of peripheral vascular disease? Aging Male 2003; 6: $217-221$.

13. Veronelli A, Masu A, Ranieri R, et al. Prevalence of erectile dysfunction in thyroid disorders: comparison with control subjects and with obese and diabetic patients. Int J Impot Res 2006; 18: 111-114.

14. Peric S, Nisic T, Milicev M, et al. Hypogonadism and erectile dysfunction in myotonic dystrophy type 1. Acta Myol 2013; 32: 106-109.

15. Blumentals WA, Gomez-Caminero A, Brown RR, et al. A case-control study of erectile dysfunction among men diagnosed with panic disorder. Int J Impot Res 2004; 16: 299-302.

16. Bookstein JJ, Valji K, Parsons L, et al. Pharmacoarteriography in the evaluation of impotence. J Urol 1987; 137: 333-337.

17. Fitzgerald SW, Erickson SJ, Foley WD, et al. Color Doppler sonography in the evaluation of erectile dysfunction. Radiographics 1992; 12: 3-17.

18. Lue TF, Hricak H, Marich KW, et al. Vasculogenic impotence evaluated by high-resolution ultrasonography and pulsed Doppler spectrum analysis. Radiology 1985; 155: 777-781.

19. Teloken PE, Park K, Parker M, et al. The false diagnosis of venous leak: prevalence and predictors. J Sex Med 2011; 8: 2344-2349.

20. Montague DK, Lakin MM. False diagnoses of venous leak impotence. J Urol 1992; 148: 1: 148-149. 
21. Kilic M, Serefoglu EC, Ozdemir AT, et al. The actual incidence of papaverine-induced priapism in patients with erectile dysfunction following penile colour Doppler ultrasonography. Andrologia 2010; 42: 1-4.

22. Zhang JJ, Qiao XH, Gao F, et al. A new method of measuring the stiffness of corpus cavernosum penis with ShearWave ${ }^{\mathrm{TM}}$ Elastography. Br J Radiol 2015; 88: 20140671.

23. Hamidi N, Altinbas NK, Gokce MI, et al. Preliminary results of a new tool to evaluate cavernous body fibrosis following radical prostatectomy: penile elastography. Andrology 2017; 5: 999-1006.

24. Pereira JA, Bilhim T, Rio Tinto H, et al. Radiologic anatomy of arteriogenic erectile dysfunction: a systematized approach. Acta Med Port 2013; 26: 219-225.

25. Patel U, Amin Z, Friedman E, et al. Colour flow and spectral Doppler imaging after papaverine-induced penile erection in 220 impotent men: study of temporal patterns and the importance of repeated sampling, velocity asymmetry and vascular anomalies. Clin Radiol 1993; 48: 18-24.

26. Roy C, Saussine C, Tuchmann C, et al. Duplex Doppler sonography of the flaccid penis: potential role in the evaluation of impotence. J Clin Ultrasound 2000; 28: 290-294.

27. Quam JP, King BF, James EM, et al. Duplex and color Doppler sonographic evaluation of vasculogenic impotence. AJR Am J Roentgenol 1989; 153: 1141-1147.

28. Altinbas NK, Gundogdu Anamurluoglu E, Oz II, et al. Real-time sonoelastography of parotid gland tumors. J Ultrasound Med 2017; 36: 77-87.

29. Ozturk A, Grajo JR, Dhyani M, et al. Principles of ultrasound elastography. Abdom Radiol 2018; 43: 773-785.

30. Gennisson JL, Deffieux T, Fink M, et al. Ultrasound elastography: principles and techniques. Diagn Interv Imaging 2013; 94: 487-495.

31. Goldstein I, Mulhall JP, Bushmakin AG, et al. The erection hardness score and its relationship to successful sexual intercourse. J Sex Med 2008; 5: 2374-2380.

32. Rosen RC, Cappelleri JC, Smith MD, et al. Development and evaluation of an abridged, 5-item version of the International Index of Erectile Function (IIEF-5) as a diagnostic tool for erectile dysfunction. Int J Impot Res 1999; 11: 319-326.

33. Turunç T, Deveci S, Güvel S, et al. The assessment of Turkish validation with 5 question version of International Index of Erectile Function (IIEF-5). Türk Üroloji Dergisi 2007; 33: 45-49.

34. Conover WJ. Practical Nonparametric Statistics. 2nd ed. John Wiley \& Sons, New York 1980; 229-239.

35. Hanley JA, McNeil BJ. The meaning and use of the area under a receiver operating characteristic (ROC) curve. Radiology 1982; 143: 29-36.

36. Mutnuru PC, Ramanjaneyulu HK, Susarla R, et al. Pharmaco penile Duplex ultrasonography in the evaluation of erectile dysfunction. J Clin Diagn Res 2017; 11: TC07-TC10.

37. Turkay R, Inci E, Yenice MG, et al. Shear wave elastography: Can it be a new radiologic approach for the diagnosis of erectile dysfunction? Ultrasound 2017; 25: 150-155.

38. Benson CB, Vickers MA. Sexual impotence caused by vascular disease: diagnosis with duplex sonography. AJR Am J Roentgenol 1989; 153: 1149-1153.

39. Virag R, Bouilly P, Frydman D. Is impotence an arterial disorder? A study of arterial risk factors in 440 impotent men. Lancet 1985; 1: $181-184$.
40. Quam JP, King BF, James EM, et al. Duplex and color Doppler sonographic evaluation of vasculogenic impotence. AJR Am J Roentgenol 1989; 153: 1141-1147.

41. Lee WH, Kim YC, Choi HK. Psycogenic versus primary organic impotence. Int J Impot Res 1994; 6: 93-97.

42. Riversi V, Tallis V, Trovatelli S, et al. Real time-elastosonography of the penis in patients with Peyronie's disease. Arch Ital Urol Androl 2012; 84: 174-177.

43. Richards G, Goldenberg E, Pek H, et al. Penile sonoelastography for the localization of a non-palpable, non-sonographically visualized lesion in a patient with penile curvature from Peyronie's disease. J Sex Med 2014; 11: 516-520.

44. Inci E, Turkay R, Nalbant MO, et al. The value of shear wave elastography in the quantification of corpus cavernosum penis rigidity and its alteration with age. Eur J Radiol 2017; 89: 106-110.

45. Zhang X, Zhou B, Miranda AF, et al. A novel noninvasive ultrasound vibro-elastography technique for assessing patients with erectile dysfunction and Peyronie disease. Urology 2018; 116: 99-105. 